\title{
COMPARATIVISMO CONSTITUCIONAL E TRADUÇÃO JURÍDICA: APROXIMAÇÕES INICIAIS AO PROBLEMA DA INCORPORAÇÃO DISCURSIVA DOS ELEMENTOS NÃO-NACIONAIS
}

\author{
CONSTITUTIONAL COMPARATIVISM AND LEGAL TRANSLATION: INITIAL \\ APPROACHS TO THE PROBLEM OF THE DISCURSIVE INCORPORATION OF NON- \\ NATIONAL MATERIALS
}

\author{
Luiz Magno P. Bastos Jr. \\ Professor de Direito Constitucional e Direitos Humanos do curso da Universidade do Vale \\ do Itajaí (graduação e programas de mestrado e doutorado em ciência jurídica). Pós- \\ Doutor em Direitos Humanos pela Universidade McGill (Canadá) e Doutor em Direito \\ Público pela Universidade Federal de Santa Catarina. Advogado publicista. \\ E-mail:1magno@univali.br; lmagno@mnadvocacia.com.br \\ Cecília Caballero Lois \\ Professora do Programa de Pós-Graduação em Direito da Universidade Federal do Rio de \\ Janeiro. Doutora em Teoria e Filosofia do Direito pela Universidade Federal de Santa \\ Catarina. Bolsista de Produtividade/CNPq (PQ2). E-mail: cecilialois@gmail.com
}

Recebido em: 20/04/2017

Aprovado em: 02/10/2017

RESUMO: O recurso a elementos não-nacionais (foreign materials) no exercício da jurisdição constitucional tem crescido significativamente, apesar de não constituir um fenômeno novo. $\mathrm{O}$ "argumento de direito comparado" representa um dos mecanismos discursivos através dos quais os tribunais podem intermediar as crescentes tensões entre sujeitos constitucionais e estabelecer pontes de ligação entre ordens normativas. Nos tribunais superiores, a abertura ao diálogo com outras realidades normativas se opera mediante esforços dos tribunais em traduzirem fragmentos externos em seus discursos sobre a constituição que são produzidos institucionalmente. Defendese neste artigo que o recurso por parte dos tribunais a elementos não-nacionais representa tanto uma forma de abertura a pluralidade de perspectivas, quanto uma estratégia discursiva voltada a produzir pontos de convergência material em torno das atualizações de sentido da constituição. Estas práticas são tratadas neste artigo como forma de tradução de modelos teóricos e de elementos normativos produzidos em outros contextos de significação. Dito de outro modo, a abertura ao diálogo com outras realidades normativas se opera mediante esforços dos tribunais em traduzirem fragmentos externos em seus discursos sobre a constituição que são institucionalmente produzidos.

Palavras-chave: Comparativismo constitucional; Argumento de Direito Comparado; Tradução jurídica; Pluralismo constitucional.

ABSTRACT: The use of non-national elements (foreign materials) in the exercise of constitutional jurisdiction has grown significantly, although it is not a new phenomenon. The "comparative law argument" represents one of the discursive mechanisms through which courts can mediate the growing tensions between constitutional subjects and create connections between normative orders. In the superior courts (as constitutional courts or appellation courts), openness 
to dialogue with other normative realities operates through the courts' efforts to translate external fragments into their institutionally produced discourses. Such discourses are instrumented through different procedures and institutional mechanisms inventoried in the context of comparative studies. In this sense, to recognize that the use of comparison consists of a strategy of argumentation implies assuming some theoretical, fundamental presuppositions. Finally, the degree of internal coherence of the argument and the weight attributed to it in the judicial discourse are directly related to the way in which the interpreter of the non-national element approaches.

Key-words: Constitutional comparativism; "comparative law" argument; Legal translation; Constitutional pluralism.

SUMÁRIO: 1. Introdução; 2. Multiplicidade de abordagens em torno da ideia de comparação constitucional; 3. Demarcação dos espaços decisórios onde são produzidas as traduções jurídicas; 3.1. Prática discursiva de referência ao argumento de direito comparado no âmbito dos órgãos decisórios não-nacionais; 3.2 Prática discursiva dos tribunais domésticos; 4.Síntese de algumas questões centrais relacionadas ao "novo" comparativismo constitucional; 5. O "argumento de direito comparado" como fator de convergência material; 5.2 Diálogo aberto e oculto: Aumento do repertório normativo e estratégia argumentativa; Conclusão; Referências bibliográficas.

\section{INTRODUÇÃO}

O recurso a elementos não-nacionais (foreign materials) no exercício da jurisdição constitucional tem crescido significativamente, fazendo com que o "argumento de direito comparado" ocupe significativo espaço nos processos de justificação judicial das decisões, mormente em casos controvertidos. Este uso, no entanto, não é um fenômeno novo1. O recurso por parte dos magistrados a experiências não-nacionais, no processo de fundamentação judicial, pode ser facilmente identificado nos mais diferentes momentos históricosde toda a tradição constitucional ocidental2.

Apesar de não ser uma realidade absolutamente nova, a relevância atribuída a estes elementos na prática discursiva dos tribunais, evidencia a ocorrência de um fenômeno mais abrangente de interpenetração das ordens constitucionais e de atuação transnacional dos tribunais nacionais.

Neste contexto, o "argumento de direito comparado" representa um dos mecanismos discursivos através dos quais os tribunais podem intermediar as crescentes tensões entre sujeitos constitucionais e estabelecer pontes de ligação entre ordens normativas. Considerando, pois, que a constituição enquanto fator de ordenação social constrói-se a partir do enfeixamento de uma pluralidade de discursos institucionalmente produzidos sobre a própria ideia de constituição.

Defende-se neste artigo que a prática dos tribunais de recurso a elementos não-nacionais representa tanto uma forma de abertura a pluralidade de perspectivas quanto uma estratégia discursiva voltada a produzir pontos de convergência material em torno das atualizações de sentido da constituição.

\footnotetext{
Assumindo, em certo sentido, a existência de uma espécie de consenso generalizado, alguns autores que abordam a questão afirmam categoricamente a existência de uma prática disseminada de recurso ao argumento de direito comparado em diferentes jurisdições, nas mais variadas tradições jurídicas. (SAUNDER, 2006; PONTHOREAU, 2005; SLAUGHTER, 1994; FERRARESE, 2009).

2 Para uma análise empírica abrangente que envolve inúmeras jurisdições vinculadas ao civil law, cf. PEGORARO (2007). Para uma abordagem ampla no âmbito dos países vinculados à tradição do common law, cf. ÖRÜCÜ (2007c). Para uma abordagem geral da prática sul-americana, cf. KLEINHEISTERKAMP (2006). Por fim, um trabalho cuidadoso de inventário da influência dos precedentes da Suprema Corte estadunidensena jurisprudência do STF, cf. DOLINGER (1990).
} 
Estas práticas são tratadas neste artigo como forma de tradução de modelos teóricos e de elementos normativos produzidos em outros contextos de significação. Dito de outro modo, a abertura ao diálogo com outras realidades normativas se opera mediante esforços dos tribunais em traduzirem fragmentos externos em seus discursos sobre a constituição institucionalmente produzidos.

Portanto, frequentemente, ao referir-se aos processos de incorporação de elementos nãonacionais, será utilizada a metáfora de discursos de tradução. Tais discursos são instrumentalizados mediante diferentes procedimentos e mecanismos institucionais inventariados no âmbito dos estudos comparatistas, que têm na noção de formantes jurídicos (SACCO, 2001) e de transferibilidade (NELKEN, 2003) importantes elementos teóricos para sua compreensão.

Feita, pois, esta precisão inicial sobre a metáfora a ser utilizada, afigura-se oportuno realizar um último esclarecimento conceitual preliminar. Neste trabalho, ao se referir à prática discursiva dos tribunais de recorrerem a elementos não-nacionais no processo de justificação judicial das decisões (giving reasons) serão utilizadas duas expressões, com sentidos complementares: o "argumento de direito comparado" e o "diálogo constitucional".

A primeira (argumento de direito comparado) será utilizada quando se estiver analisando a questão das práticas discursivas sob o ponto de vista interno ao sistema doméstico, ou seja, quando o acento for dado à utilização por parte dos magistrados de referências ao "direito não-nacional" como "argumento justificativo" (argument justificatif) de sua decisão3. (PONTHOREAU, 2005). Enquanto a segunda (diálogo constitucional) será utilizada quando se estiver discutindo as interações institucionais realizadas pelos tribunais por intermédio de sua prática discursiva (JACOBSOHN, 2004; TOUFAYAN, 2010).

A fim de levar a termo este artigo, o trabalho será dividido em quatro seções. Na primeira, será feito um breve inventário sobre a multiplicidade de abordagens em torno da ideia de comparação constitucional, com especial ênfase, na implementação destes transplantes/interpretações por parte do Poder Judiciário. Na segunda, serão apresentados os dois tipos principais de espaços decisórios em que se realizam os discursos de tradução (os órgãos não-nacionais e os tribunais domésticos) a fim de que sejam apresentados os espaços institucionais de interação. Na terceira, será realizada a identificação de alguns pontos centrais que vêm sendo apresentados como problemáticos no âmbito deste novo "comparativismo constitucional". Na quarta, será feita proposta de leitura da prática discursiva destes processos de tradução como fator de formação de pontos de convergência material. Ao final, portanto, serão feitas breves considerações sobre os aspectos mais relevantes aqui discutidos.

\section{MULTIPLICIDADE DE ABORDAGENS EM TORNO DA IDEIA DE COMPARAÇÃO CONSTITUCIONAL}

Não há expressão unívoca que englobe, sem controvérsias, o debate em torno da circulação e transferibilidade das ideias jurídicas, das normas, de práticas legais e de instituições jurídico-políticas. É possível identificar um sem-número de expressões que englobam, de um lado, esta dimensão mais abrangente -empréstimo constitucional (TUSHNET, 1999), transplantes

\footnotetext{
3 Expressão esta que pressupõe o reconhecimento de que o processo de interpretação da Constituição pelos tribunais resulta de um encadeamento de argumentos (e contra-argumentos) que possibilitam uma tomada de uma decisão.(PONTHOREAU, 2005, p. 169). Para autora, a mera adoção de referência ao direito estrangeiro desprovida de uma autêntica comparação de direitos, pelo papel desempenhado na justificativa da tomada de decisão, justifica a utilização da expressão "argumento de direito comparado" (PONTHOREAU, 2005, p. 169). Em sentido similar, pode ser mencionada a definição de DAMMAN (2002, p. 520), para quem a expressão inclui "any reasoning that somehow refers to foreign law"; apesar desta definição genérica o autor identifica quatro usos distintos em que a incorporação de referência ao direito comparado é utilizado nos processos de justificação judicial: comparação avaliativa; comparação intencionalista; comparação textual e, por fim, comparação baseada em argumento de autoridade.
} 
jurídicos (WATSON, 1996), circulações de modelos (PEGORARO, 2007), imitação jurídica (SACCO, 2001), migrações constitucionais (CHOUDRY, 2006; SCHEPPELLE, 2003), irritações jurídicas (TEUBNER, 1998a)- de outro lado, circunscrevem-se especificamente ao emprego de elementos não-nacionais nas decisões judicias -circulação horizontal de argumentos (LOLLINI, 2007), diálogo transjudicial e transfertilização (SLAUGHTER, 1994; 2004), influência transconstitucional (CHOUDHRY, 1999), transplante judicial (ACKERMAN, 1997), empréstimo de precedentes judiciais (SAUNDERS, 2006), jogos de interpretação cruzada (DELMASMARTY, 2006; 2009). Estas expressões são utilizadas nas mais variadas acepções e envolvem um conjunto muito vasto de fenômenos relacionados aos processos de circulação de modelos constitucionais4.

A pluralidade de abordagens sobre a temática sugere uma escolha preliminar em relação à metáfora que melhor seja capaz de exprimir, de plano, os pressupostos teóricos que informam a percepção sobre os problemas enfrentados5, ou seja, o uso de metáforas lança luzes, de plano, aos aspectos-chave reconhecidamente importantes para a perspectiva assumida (SCHEPPELE, 2006, p. 347). Em que pese a existência de bons argumentos que militam em favor da ideia de migração constitucional e de transfertilização, sobretudo, quando se tem por referência as expressões transplante jurídico6 ou empréstimo constitucional, a expressão que mais se compraz com as ideias trazidas neste artigo consiste em "tradução jurídica" (legal translation).

Por outro lado, a fim de lidar com os desafios relacionados à tensão entre a diferença e a semelhança, marco epistemológico constitutivo dos estudos comparatistas, CURRAN (2006) recorre aos estudos sobre a linguagem para lançar as bases para a construção de um modelo cognitivo para o direito comparado que se valha da noção de tradução como mecanismo central de construção de sentido nos discursos de significação7. Desta forma, militam em favor desta metáfora, algumas ideias por ela veiculadas, já que a ideia de tradução: (i) chama a atenção para uma distinção entre o texto original e o texto traduzido; (ii) captura o elemento de transformação que a ideia ou prática jurídica experimenta no processo de tradução de um determinado contexto para outro; bem como, (iii) ressalta a transformação experimentada pelas práticas sociais e linguísticas sob a influência do texto traduzido. (LANGER, 2004, p. 33-34).

As diversas abordagens que tratam do fenômeno da circulação de modelos constitucionais podem ser reunidas em dois grandes grupos: o primeiro, vinculado aos grandes temas do direito comparado (direito constitucional comparado em uma versão mais tradicional); o segundo reúne estudos que se ocupam da análise de práticas institucionais (sobretudo, dos

\footnotetext{
4 YAZBEK (2001) apresenta uma visão panorâmica sobre as diferentes expressões que vêm sendo usadas para reportar-se às facetas do fenômeno da transferência e da circulação de modelos jurídicos em geral. Neste artigo, o autor se preocupa com a sistematização de propostas teóricas e de modelos explicativos dos processos de transferência os quais, segundo entende, devem ser melhor apreendidos pelos juristas.

5 Sobre o valor das metáforas, especificamente em relação ao problema das "transferências jurídicas" e da interface entre diferentes disciplinas científicas, NELKEN (2001, p. 29) assinala que "[t]he value of the metaphors can only lie in their heuristic possibilities - the way they lead us to think in new and imaginative ways, in the present case, about the processes of legal transfer".

6 Trata-se expressão consagrada no âmbito dos estudos de direito comparado e sua difusão é devida à obra seminal de WATSON (1993) que conferiu novo impulso aos estudos dos processos de difusão do direito. Uma reflexão profunda sobre as limitações desta perspectiva e a ênfase atribuída aos aspectos mecânicos e institucionais por ela evocados pode ser encontrada em NELKEN (2001).

7 A opção por esta metáfora se coaduna com a crítica formulada por FRANKENBERG (1985, p. 414) em relação ao mainstream do direito comparado baseada na ideia de que o direito comparado exige uma "dialética de aprendizagem" que se traduz no reconhecimento de um diálogo necessário entre o estabelecido e o novo. Isto se materializa no esforço de distanciamento e de diferenciação.De acordo com o autor, o distanciamento "de-centers our world-view and thus establishes what might be called objectivity. (...)", enquanto que a diferenciação "an thereby prevent the traveler-compartist from regarding the world only in terms of the language of security and selfunderstanding and from leveling others with old concepts, imagery, and experience." (1985, p. 414-415).
}

Revista de Direito Brasileira | São Paulo, SP | v. 20 | n. 8 | p. 62-80 |Mai./Ago. 2018 
tribunais) que se engajam em processos de "diálogo constitucional" (comparativismo constitucional).

O primeiro grupo procura dar maior ênfase a questões de índole metodológica e apresenta um maior apelo e difusão entre os autores de tradição civilista8. Para os autores representativos deste grupo, o debate em torno dos transplantes constitucionais se processa no marco teórico da ciência comparativa e da história constitucional. Exemplificativamente, podem ser agrupadas tais abordagens da seguinte forma: (a) leituras que buscam identificar os movimentos constitucionais e o processo de expansão das ideias liberal-democratizantes e das instituições republicanas, em uma perspectiva de história do constitucionalismo e das ideias políticas (VAN CAENEGEM, 1995; MATEUCCI, 1998; FIORAVANTI, 1998, 2000; SANCHEZ AGESTA, 1974); (b) a identificação da existência dos grandes sistemas constitucionais, reconstruídos através de análise comparativa de processos de diferenciaçãoaproximação (macrocomparação) (DI RUFFIA, 2000; GARCÍA-PELAYO,1993; DE VERGOTINNI, 2004; SANCHEZ AGESTA, 1974; DAVI, 1996); (c) esforços de identificação de processos de aproximação e de recíproca influência entre estes diferentes modelos, ora enfatizando os aspectos genéticos (HENKIN; ROSENTHAL, 1988), ora enfatizando o aspecto dinâmico de recepção/envio de institutos jurídicos (paradigma dos níveis textuais - HÄBERLE, 1996); ou ainda, (d) esforços de identificação de elementos comuns de direito partilhados, não obstante as individualidades e particularidades nacionais, por determinados países ocidentais, tendo em vista, a existência de uma tessitura cultural interconectada e com elementos comuns (HÄBERLE, 1996; CANÇADO TRINDADE, 2002).

O segundo agrupamento, por seu turno, ganha maior proeminência no ambiente cultural dos países de tradição associada ao common law e nas discussões que envolvem o direito europeu e a aplicabilidade doméstica do direito internacional (com especial referência ao direito internacional dos direitos humanos)9, e estão em maior ou menor grau associados à ideia de um processo de internacionalização da prática judicial e do constitucionalismo em escala global.

Neste trabalho, pretende-se exatamente dedicar-se a esta última perspectiva, mais precisamente, em identificar de que forma os processos de tradução jurídica materializam-se através do recurso ao argumento de direito comparado e dos mecanismos de diálogos constitucionais que se estabelecem entre as diferentes instâncias decisórias (judiciais ou quasejudiciais) nos espaços doméstico, internacional e transnacional de regulação.

\section{DEMARCAÇÃO DOS ESPAÇOS DECISÓRIOS ONDE SÃO PRODUZIDAS AS TRADUÇÕES JURÍDICAS}

Os discursos constitucionais projetam-se para além do espaço de regulação doméstico e, com isso, mediante o estabelecimento de processos de recíprocos cometimentos, pretendem transplantar as funções de integração e de integridade, modernamente atribuídas à constituição, para os espaços de integração regional (PERNICE, 2002), para o espaço internacional (DE WET, 2006; FASSBENDER, 1998) e, até mesmo, para os espaços transnacionais privados (TEUBNER, 2004)10. A autoafirmação destes discursos e o seu entrelaçamento com os espaços de regulação

\footnotetext{
8 Uma discussão pormenorizada em torno dos desafios metodológicos ligados ao direito comparado e a dificuldade clássica em demarcar o seu estatuto epistemológico foram feitas em trabalho anterior. (BASTOS JUNIOR, 2006).

9 Há autores que defendem que a identificação da estrutura de compreensão do fenômeno jurídico é, em grande parte, influenciada pela linguagem. No caso em questão, é a língua inglesa que se impõe como língua oficial nos países de tradição do common law e o discurso do direito internacional e dos direitos humanos, em grande parte, se veicula mediante o idioma inglês. (CARVALHO, 2007).

10 A questão relacionada ao deslocamento da gramática constitucional para outros espaços que não o espaço nacional representa aquilo que, neste trabalho, convencionou-se chamar de "problema de territorialidade". Uma breve discussão sobre a questão e as implicações associadas à ideia de pluralismo constitucional foi feita durante a sessão 5.2.
} 
multifacetados processam-se através de diferentes mecanismos institucionais e de estratégias discursivas.

Ao se analisarem os discursos produzidos em cada um desses espaços decisórios, a lógica de construção do raciocínio associada ao recurso ao "argumento de direito comparado", resulta na tradução, para o interior do sistema jurídico em questão, de elementos textuais extrassistemáticos (não-nacionais). Assim, esta estratégia argumentativa opera múltiplas funções (reveladas e implícitas) no processo de construção judicial de sentidos normativos e é justamente por intermédio deste recurso que muitas das formas de interação representadas pela ideia de diálogo constitucional se manifestam. Neste contexto, o recurso ao "argumento de direito comparado" representa, nos termos defendidos neste trabalho, um sinal visível por meio dos quais os diálogos constitucionais se constituem.

Desta forma, ao traduzir um elemento normativo extrassistemático e inseri-lo como parte integrante do processo de construção de sentidos normativos, o órgão decisório recorre a ele como uma autoridade persuasiva11. Ao discutirem sobre o grau de vinculação dos tribunais às razões veiculadas pelo direito não-nacional (em especial, dos precedentes judiciais), em geral, os autores contrapõem a ideia de força persuasiva (persuasive reason) destes elementos à noção de força vinculante (binding force ou authoritative reason) (DAMMAN, 2002; JACKSON, 2001; TUSHNET, 1999; PARRISH, 2007).

Nos discursos sobre a existência de diálogos transjudiciais, a noção de autoridade persuasiva ocupa um lugar de destaque na compreensão do enfeixamento de argumentos e nos mecanismos de alocação de autoridade entre as cortes. A primeira associação feita entre o recurso ao elemento não-nacional e a natureza meramente persuasiva, costuma ser atribuída a GLENN (1987), passando a ser expressamente assumida como um dos valores centrais para a edificação da nova ordem mundial, nos termos defendidos por SLAUGHTER (2004a).

Apesar da lógica de construção do raciocínio operar em termos muito similares, as diferentes instâncias decisórias recorrem a esta estratégia discursiva a partir de justificativas muito díspares, razão pela qual se afigura interessante demarcar os dois principais contextos de aplicação, quais sejam: a decisão das cortes judiciais (ou quase-judiciais) no âmbito de regulação inter e transnacional e a decisão dos tribunais domésticos.

\subsection{PRÁTICA DISCURSIVA DE REFERÊNCIA AO ARGUMENTO DE DIREITO COMPARADO NO ÂMBITO DOS ÓRGÃOS DECISÓRIOS NÃO-NACIONAIS}

Este conjunto de órgãos decisórios envolve um universo muito díspar de organizações internacionais, supranacionais e não-governamentais. Estes órgãos decisórios operam em estrita observância à racionalidade inerente aos regimes jurídicos especiais onde se situam (sejam eles inter(supra)estatais, intergovernamentais ou eminentemente privados) e ostentam graus variados de institucionalização. Esta institucionalidade variada costuma ser associada à extensão de sua competência jurisdicional e à densidade normativa dos regimes jurídicos aos quais estão vinculados. Ademais, seus procedimentos decisórios operam através de diferentes mecanismos de acionamento e de interação entre os litigantes e entre estes órgãos decisórios e as demais instâncias de deliberação correlatas.

Em que pesem estas múltiplas variáveis, é possível identificar algumas tendências comuns identificadas nestes diferentes níveis jurisdicionais: (i) a existência de uma forma de

\footnotetext{
11 PARRISH (2007, p. 649) refere-se ao debate norte-americano em torno do uso/não-uso do argumento de direito comparado como uma "storm in a teacup". No início do artigo ele afirma duas questões que reputa serem óbvias: (i) o argumento de direito comparado não é legalmente vinculante; (ii) inexiste qualquer imposição legal por parte das cortes estrangeiras e, mesmo internacionais, de que os tribunais nacionais adotem determinada condição interpretativa. De acordo com o autor, tais esclarecimentos se fazem necessários por conta do caráter retórico e apaixonadamente a-científico que se converteu a discussão sobre esta temática, em solo norte-americano.
}

Revista de Direito Brasileira | São Paulo, SP | v. 20 | n. 8 | p. 62-80 |Mai./Ago. 2018 
operação muito próxima à da tradição do common law, inclusive tendo na língua inglesa o veículo preferencial de comunicação; (ii) tendência de crescimento da juridicidade (tribunalização) dos procedimentos e da fundamentação jurídica de suas decisões, tanto em instâncias com forte conotação política (e.g., Conselho de Segurança da ONU), quanto em instâncias decisórias não-estatais com altíssimo grau de especialidade funcional (e.g. a London Court of International Arbitration); (iii) esforços de reconhecimento da existência de normas gerais de direito internacional que operam como elementos de sedimentação e de ligação entre os diferentes regimes fragmentados, sobretudo nos órgãos decisórios baseados em atos convencionais (desenvolvimento de cláusulas de due process em diversas searas decisórias); (iv) necessidade de desenvolver regras e critérios para o enfrentamento de conflitos entre jurisdição e entre elementos normativos produzidos em marcos regulatórios diferenciados (aplicabilidade de regras de conflitos de lei nos espaços transnacionais de regulação); e, por fim, (v) a necessidade, em escala diferenciada, de articulação e de cooperação com as instâncias estatais domésticas (sobretudo, os órgãos judiciários) na condição de atores essenciais para a executoriedade (enforceability), a observância (compliance) e efetividade (effectiveness) das obrigações (internacionais ou não) reconhecidas nestes órgãos decisórios.

A partir deste conjunto de elementos é possível identificar a existência de uma prática recorrente de referências a elementos extrassistemáticos no âmbito destes diferentes órgãos que envolvem os diferentes momentos decisórios: (i) a definição (ou não) de sua competência para resolver o litígio/problema suscitado; (ii) a identificação do direito aplicável; e (iii) a construção das estratégias discursivas para prover maior grau de adesão (discursos sobre a legitimidade/correção do resultado alcançado).

Para os propósitos deste trabalho, em face do maior engajamento com os tribunais nacionais, as cortes internacionais e os tribunais supranacionais afiguram-se dotados de maior relevância. No âmbito destes últimos loci, o recurso a elementos de direito comparado traduz-se em uma prática fartamente consolidada e vem sendo constantemente invocada como um método preponderante para o julgamento das questões perante tais cortes. Esta estratégia afigura-se particularmente relevante quando se pretende definir o conteúdo e o alcance dos princípios gerais de direito e o reconhecimento de regras costumeiras válidas.

Esta prospecção de fontes nacionais cumpre um duplo propósito: (a) identificar elementos comuns aos diferentes universos normativos a fim de preencher o conteúdo e de definir o alcance dos princípios gerais de direito (KOOPMANS, 1996); e (b) em particular, no âmbito do direito comunitário, aumentar o grau de legitimidade das decisões em nível comunitário e, com isto, estimular que as cortes nacionais, responsáveis pela implementação das decisões das cortes comunitárias em regime de coordenação judicial (SCHUTTER, 2004), possam vincular-se mais "espontaneamente" às diretrizes fixadas em seus julgados (GROSSFELD, 2000).

Ademais, em especial no âmbito dos sistemas de proteção de direitos humanos, tem sido recorrente o diálogo entre cortes, sobretudo pela tradução das decisões da Corte Europeia de Direitos Humanos, tanto explicitamente pela Corte Interamericana de Direitos Humanos, quando implicitamente pela Comissão de Direitos Humanos (MCCRUDDEN, 2000). Neste sentido, estes órgãos decisórios engajam-se deliberadamente em um processo de transfertilização e de reconhecimento expresso da complementariedade entre os diferentes sistemas de proteção dos direitos humanos (CANÇADO TRINDADE, 2003).

\subsection{PRÁTICA DISCURSIVA DOS TRIBUNAIS DOMÉSTICOS}

Como antes salientado, as referências a experiências não-nacionais sempre foram muito comuns (SAUNDERS, 2006). No entanto, a forma "tradicional" com que até então a prática de transfertilização ocorria no âmbito das diferentes tradições jurídicas tem sido objeto de profundas 
ressignificações. Estes processos de renovação discursiva apontam para a ocorrência de transformações existenciais em relação à forma de compreender a identidade constitucional e os mecanismos de produção de integração por intermédio dos discursos sobre a constituição.

Esta forma "tradicional" de conceber o recurso ao argumento de direito comparado, no âmbito dos países vinculados à tradição do common law, limita-se à existência de um diálogo entre cortes do Commonwealth as quais de alguma forma, encontravam-se até bem pouco tempo sujeitas a uma espécie de supervisão do Privy Council12. Os diferentes esforços de sistematização da prática das cortes da Austrália e Nova Zelândia (SAUNDERS, 2006), na Irlanda (MCCRUDDEN, 2000; JACOBSOHN, 2010), no Reino Unido (ÖRÜCÜ, 2007c), em Israel (JACOBSOHN, 2004; 2010); na Índia (SCOTTI, 2010) dão conta desta tendência em seguir este padrão. Situação particularmente diferenciada ocorre com a Suprema Corte norteamericana e sua recalcitrância em engajar-se em comparação constitucional e as Cortes Constitucionais canadense e sul-africana envolvidas em processos de intenso engajamento com diferentes constelações normativas de índole constitucional.

Em relação à corte canadense, atribui-se este engajamento ativo à relativamente recente promulgação de sua Carta de Direitos (The Canadian Charter of Rights and Freedoms, de 198213) e a questão, permanentemente controvertida, da divisão da comunidade política interna (CHOUDHRY, 1999; HARDING, 2003; GENTILI, 2010); e, a segunda, impulsionada pela sua previsão constitucional (art. 39) que lhe impele a engajar-se em conversação tanto com o direito internacional, quanto com as demais experiências constitucionais não-nacionais (RAUTENBACH, 2010; LOLLINI, 2007).

Por outro lado, no âmbito dos países vinculados à tradição do civil law, em face de suas peculiaridades culturais, o recurso ao argumento de direito comparado ganha outra coloração. A forma com que se processam as demandas por abertura discursiva articula-se com a lógica de argumentação das decisões judiciais, cujas cadeias argumentativas são estruturadas dedutivamente.

Nestes termos, a feição tradicional do recurso ao argumento de direito comparado se compraz com a crença, ainda largamente difundida, de que o magistrado deve julgar em conformidade com o direito que se lhe apresenta como um objeto (pronto e acabado) a ser descoberto pelo labor hermenêutico. No processo de (re)construção do comando normativo aplicável ao caso, as cortes recorrem preferencialmente à doutrina, utilizando-se das referências a julgados como argumentos de autoridade e de reforço de uma posição pré-anunciada. 14

Esta característica fez com que, até bem pouco tempo, os manuais de direito dessem muito pouca importância à análise das decisões das cortes. O esforço de identificação de casos paradigmáticos em determinados conjuntos normativos é recente e se coaduna com aquilo que vem sendo denominado de jurisprudencialização do direito (em especial, do direito

12 Alguns fatores, por obviedade, podem explicar esta característica e, sobretudo, esta predileção por referências ao case-law dos países do Commonwealth: (i) a língua inglesa; (ii) a origem comum do direito e a forma de sua estruturação assentada na tradição do common law; (iii) a manutenção da prática de inventariar precedentes similares em outras jurisdições para prover a ideia de integridade do sistema jurídico e para afastar o óbice de eventual objeção de legitimidade contramajoritária dos juízes; (iv) a estabilidade e autoridade de algumas jurisdições, notadamente, inglesas e norte-americana, contribuem para a difusão do rule of law como reforço das garantias institucionais do Poder Judiciário local.

13 A Carta de Direitos canadense constitui a primeira parte do Ato Constitucional de 1982, que introduziu uma série de alterações na Constituição canadense, conferindo especial expansão do judicial review através da adoção da cláusula de supremacia, de acordo com a qual "the Constitution of Canada is the "supreme law of Canada", and any law inconsistent with it is of no force or effect." (art. 52 do Ato Constitucional).

14 MEDINA (2004) realiza interessante análise sobre os processos de recepção (e de transformação) ocorridos nos países periféricos (em especial, na América Latina) de autores clássicos de teoria do direito que constituem aquilo que ele denomina de Teoria Transnacional do Direito (TTD). Apesar dele não enfrentar expressamente a questão relacionada ao diálogo judicial, são bastante pertinentes suas análises sobre o efeito transformador da "leitura" local sobre a TTD e sobre o papel legitimador que esta incorporação desempenha no discurso jurídico local.

Revista de Direito Brasileira | São Paulo, SP | v. 20 | n. 8 | p. 62-80 |Mai./Ago. 2018 
constitucional) (ROUSSEAU, 1998). Trata-se do reconhecimento de um papel proeminente atribuído às cortes (em especial à Corte Constitucional) no processo diário de (re)estruturação do direito constitucional (ALEXY; DREIER, 1997)15.

Neste ambiente cultural, o fenômeno da circulação de modelos jurídicos é tão (ou mais) frequente que a prática de envio/recepção na tradição contraposta. Todavia, no contexto de justificação das decisões judiciais, o recurso à prática estrangeira é, muitas vezes, deliberadamente escondido, como ressaltam LEGAIS (1997, p. 113) e PONTHOREAU (2005, 17-18) ao analisarem a jurisprudência das cortes superiores francesas. Ou, mais frequentemente, é introduzido na prática judicial por intermédio de literatura especializada (DROBNIG, 1997). Assim, de acordo com DROBNIG (1997), o principal veículo de transposição de modelos constitucionais, no exercício da jurisdição constitucional, consiste na incorporação de lições doutrinárias, já que, de acordo com uma perspectiva tradicional, a análise direta do case law das cortes é associada a aproximações parciais a serem evitadas. Esta prevenção em torno deste processo de engajamento decorreria da impossibilidade de uma adequada aproximação contextual no âmbito das práticas de justificação judicial da decisão.

Todavia, este quadro, em ambos os cenários, tem sofrido mudanças significadas, como se defende neste trabalho. A compreensão do recurso ao direito comparado ou mesmo o impulso (maior ou menor) à juscomparação nos processos judiciais está relacionada a um conjunto multifacetado de fatores que serão, somente exemplificativamente, apresentados aqui: (a) maior ou menor grau de abertura na cultura jurídica e política do país ao fenômeno da recepção jurídica; (b) forma como a corte se vincula ao sistema de fontes e à utilização destes materiais normativos no processo de argumentação judicial16; (c) forma com que o texto constitucional ou as próprias cortes nacionais compreendem a relação entre direito interno e direito internacional (interpenetração das ordens jurídicas) e as bases culturais que conectam a experiência nacional com experiências estrangeiras (vinculação a um conjunto de tradições compartilhadas e relação de parentesco jurídico).

Estes fatores concorrem, frequentemente, para que sejam opostas a esta estratégia inúmeras objeções que exigem diferenciadas formas de justificação que, a um só tempo, legitimem o recurso a elementos não-nacionais para a compreensão da constituição doméstica, sem com isto colocarem em xeque a própria base de legitimação para sua atuação (tribunais domésticos como intérpretes da constituição nacional), questões estas que serão enfrentadas adiante.

\footnotetext{
15 A corte constitucional, como guardiã final da constituição, emerge como palco de acirradas demandas por reconhecimento de direitos e de disputas políticas decorrentes, em grande parte, de seu papel como árbitro entre os poderes e como limite contra-majoritário na proteção das liberdades. Esta proeminência destas cortes decorre da promulgação de decisões fundamentadas em uma perspectiva interpretativa de cunho principiológico e dotadas de posturas assumidamente criativa e intervencionista. Além, é claro, do efeito vinculante de suas decisões. Esta guinada é tão significativa que alguns autores referem-se a esta recente preocupação da doutrina como uma vinculação "quase canônica" ao case-law da Corte Constitucional (SCHLINK, 1994).

16 Em relação aos países de tradição civilista, a lógica de argumentação das decisões das cortes estrutura-se precipuamente a partir de argumentos dedutivos: da identificação do comando da lei à aplicação ao caso analisado. Esta vinculação parece ainda estar presa à crença de que o magistrado deve julgar em conformidade com o direito que se lhe apresenta como um objeto (pronto e acabado) a ser descoberto pelo labor hermenêutico. No processo de (re)construção do comando normativo aplicável ao caso, as cortes recorrem preferencialmente à doutrina, utilizandose das referências a julgados como argumentos de autoridade e de reforço de uma posição pré-anunciada. Esta característica fez com que, até bem pouco tempo, os manuais de direito dessem muito pouca importância à análise das decisões das cortes. O esforço de identificação de casos paradigmáticos em determinados conjuntos normativos é recente e se coaduna com aquilo que vem sendo denominado de jurisprudencialização do direito (em especial, do direito constitucional) (ROUSSEAU, 1998). Trata-se do reconhecimento de um papel proeminente atribuído às cortes (em especial à Corte Constitucional) no processo diário de (re)estruturação do direito constitucional (ALEXY; DREIER, 1997).
} 


\section{SÍNTESE DE ALGUMAS QUESTÕES CENTRAIS RELACIONADAS AO "NOVO" COMPARATIVISMO CONSTITUCIONAL}

O que torna o recurso a esta "estratégia discursiva"ainda mais atrativo é o fato de que este "diálogo" confere aos tribunais um significativo grau de liberdade em "atualizar o sentido da constituição" à medida que amplia sobremaneira o arsenal argumentativo dos seus magistrados. Este aumento de poder dos tribunais, em escala global (TATE; VALLINDER, 1995; HIRSCHL, 2007; STONE, 2009), a um só tempo reforça o seu papel institucional no âmbito interno de cada Estado e, a característica que mais chama a atenção no contexto deste trabalho, confere-lhes um sobrelevado papel de acomodação das tensões eventualmente existentes entre os diferentes regimes jurídicos (FERRARESE, 2009), reforçando a ideia de que a constituição opera como instrumento de mediação entre o doméstico e o global (JACKSON, 2010).

Este processo realiza-se (daí a sua força simbólica) sem que se rompa frontalmente com a tradição discursiva dos operadores do direito, nem que provoque o abalo da própria legitimidade do órgão judicial.

Isto é possível, dentre outras razões, porque contra os ataques à legitimidade deste recurso, argumenta-se que a autoridade das fontes nacionais mantém-se incólume já que se trata "tão-somente" da utilização de um método interpretativo com caráter meramente persuasivo; contra os ataques à autoridade dos tribunais constitucionais, ao serem introduzidas as noções de diálogo e cooperação entre as cortes, pode-se reafirmar retoricamente o papel atribuível aos magistrados de guardiães da Constituição (logo, da própria soberania nacional).

É certo que, em ambos os casos, as funções de estabilidade e ordenação atribuídas à constituição e à ideia de supremacia constitucional são re-especificadas a fim de que passem a incorporar diferentes esferas de normatividade produzidas para além do Estado nacional, ampliando a dimensão do "pacto de compromissos" modernamente reconhecida à constituição17.

Não obstante algumas resistências eloquentes ao uso do argumento de direito comparado por parte de algumas jurisdições18, esta predisposição ao "diálogo" possui uma grande penetração no universo jurídico, pois evoca inúmeras pré-compreensões (em certo grau, compartilhadas) em torno da ideia de legitimidade do direito19 e do papel a ser desempenhado pelo Poder Judiciário.

O que se poderá perceber, é que em razão desta sua atuação conformadora e compatibilizadora, os tribunais nacionais convertem-se em importantes atores na arena transnacional, conquanto o seu grau de influência varie vertiginosamente de acordo com uma plêiade de elementos, quais sejam: (i) o variado grau de estabilidade institucional (e de reconhecimento de autoridade); (ii) a "qualidade" das razões públicas empregadas no processo de argumentação judicial; (iii) o grau de engajamento do tribunal com elementos não-nacionais no processo de fundamentação das decisões; (iv) a capacidade de inserção de seus magistrados em fora internacionais (acadêmicos e interinstitucionais); (v) pela acessibilidade linguística (leia-se, a conversão em inglês de seus principais julgados) e disponibilidade de acesso (disponibilização na rede); e, ainda, (vi) pela utilização de suas decisões por organizações com atuação

\footnotetext{
17 Esta compreensão da existência de normatividade além do Estado materializa-se através de formulações que, como a ideia de soberania constitucional proposta por ZAGREBELSKI (1995), converte a constituição em um "compromisso de possibilidades".

18 Tem sido fartamente documentado o debate sobre a utilização de fontes não-nacionais pela Suprema Corte norteamericana (PERJU, 2007; PARRISH, 2007). Por outro lado, na experiência continental europeia, é igualmente bastante pronunciada a resistência do Conselho Constitucional francês (LEGAIS, 1999) e da Corte Constitucional Belga, antiga Corte de Arbitragem (POIRIER, 2008) ao recurso a elementos não-nacionais na fundamentação de suas decisões (KIIKERI, 2001).

19 Tanto é assim que, no contexto da presente pesquisa, a busca por encontrar princípios universais e o reconhecimento de uma vocação universalista dos direitos humanos constituem justificativas frequentemente utilizadas pelos magistrados e pela doutrina (DUPRE, 2003; CHOUDHRY, 1999; MCCRUDDEN, 2000).
}

Revista de Direito Brasileira | São Paulo, SP | v. 20 | n. 8 | p. $62-80$ |Mai./Ago. 2018 
transnacional como parte da estratégia de determinados segmentos para o reconhecimento de uma pauta de direitos.

Apesar destes diferentes esforços de racionalização sobre os possíveis motivos que impulsionam (ou impelem) ao engajamento em tradução (transladação de modelos/formas jurídicas), creio que dois fatores acabam por interferir diretamente nesse impacto sobre as práticas dos tribunais, aquilo que AJANI (1995) qualifica de "chance e prestígio" como sendo os fatores decisivos para essa realidade. $\mathrm{O}$ primeiro, está relacionado a fatores meramente acidentais relacionados a percursos acadêmicos e/ou contatos não-estruturados a elementos não-nacionais que possam ser utilizados no processo de tradução jurídica. $\mathrm{O}$ segundo, está diretamente relacionado com a pretensão da corte em tomar por empréstimo o prestígio (reputação) do fragmento normativo (dispositivo legal e/ou decisão de cortes) traduzido.

\section{O “ARGUMENTO DE DIREITO COMPARADO" COMO FATOR DE CONVERGÊNCIA MATERIAL}

A partir da adoção destas premissas teóricas, o "argumento de direito comparado" representa um importante instrumento de articulação dessas alternativas. Ademais, pode ainda ser compreendido como uma resposta a demandas "internas" por formação de novos pontos de convergência material (problema da congruência normativa) e como um artifício para reforço discursivo da autoridade das decisões dos tribunais nacionais ante a possibilidade de confrontação por esferas decisórias não-estatais (problema da soberania).

Nestes termos, a soberania é limitada pelo dever de acomodação e de reconhecimento da diferença e a legitimidade dos tribunais passa a depender da demonstração da inclusão do maior número de perspectivas alternativas ao processo de tomada de decisões. A soberania dos órgãos estatais (e, por conseguinte, a autoridade dos tribunais constitucionais) não decorreria tãosomente da sua "capacidade de decidir" (vontade soberana), mas do grau de legitimidade material (capacidade de acomodação das diferenças) das decisões políticas (e judiciais) a serem por si adotadas.

Transplantando estas ideias para a análise do objeto desta pesquisa, o argumento de direito comparado20, portanto, consiste em uma ferramenta (estratégia discursiva) que permite aos tribunais produzirem, institucionalmente, novos pontos de convergência material.

Sob o ponto de vista da realidade intracomunitária, esta articulação de elementos nãonacionais nas práticas discursivas dos tribunais permite seja "internalizada" a crítica acerca de suas próprias pré-compreensões (dimensão negativa) e sejam enfeixadas múltiplas alternativas resultantes do compromisso com o pluralismo (dimensão positiva). Frise-se que a referência à constituição nacional como parâmetro de sua atuação acaba por reforçar o fundamento formal de legitimidade de sua atuação e, como dito antes, inovar sem romper com a tradição discursiva da comunidade política (polity).

\subsection{O RECURSO AO ARGUMENTO DE DIREITO COMPARADO COMO "MAXIMIZAÇÃO DE ALTERNATIVAS" CONSTITUCIONAIS NO ÂMBITO DO PLURALISMO COMPREENSIVO}

20 O autor lista um conjunto de ferramentas constitucionais através dos quais seria possível realizar as mediações defendidas na sua concepção de pluralismo compreensivo, tais como: cláusula de federalismo, princípio de subsidiariedade, milliet system, margem de apreciação, máxima de proporcionalidade e a ponderação. $\mathrm{O}$ autor não inclui expressamente o recurso ao argumento de direito comparado como uma ferramenta útil à maximização do pluralismo compreensivo. Portanto, esta associação resulta de esforço de sistematização desta proposta de pesquisa. Apesar de não incluir este elemento, em outro trabalho em que analisa a prática da corte húngara relacionada à liberdade de expressão, o autor (juntamente com András Sajo) assinala a importância do recurso ao elemento nãonacional para a abertura dialógica do horizonte de sentido aplicável ao texto constitucional (ROSENFELD, SAJO, 2007). 
De acordo com o argumento central aqui desenvolvido, o recurso por parte dos tribunais nacionais ao diálogo constitucional ad extra cumpre a uma função muito importante, qual seja, a de produzir novos pontos de convergência material em um cenário de incremento de demandas por reconhecimento e de decisões conflitantes sobre o sentido atual da constituição. A ideia de que estes pontos de convergência material podem ser produzidos pela atuação dos tribunais em cenários de profundo dissenso e de pluralismo radical se materializa, na visão de ROSENFELD, a partir de um conjunto de ferramentas que permitem a articulação entre diferentes pontos de vista, tais como: a cláusula de federalismo, princípio de subsidiariedade, milliet system, margem de apreciação, máxima de proporcionalidade e a ponderação. E, entre estas ferramentas, o recurso ao elemento não-nacional para engajamento em processos de tradução jurídica permite a abertura dialógica do horizonte de sentido aplicável ao texto constitucional (ROSENFELD, SAJO, 2007).

Sob o ponto de vista da realidade intracomunitária, esta articulação de elementos nãonacionais nas práticas discursivas dos tribunais permite sejam "internalizadas" a crítica acerca de suas próprias pré-compreensões (dimensão negativa) e sejam enfeixadas múltiplas alternativas resultantes do compromisso com o pluralismo (dimensão positiva). Frise-se que a referência à constituição nacional como parâmetro de sua atuação acaba por reforçar o fundamento formal de sua legitimidade e, como dito antes, permite às cortes inovarem sem romper com a tradição discursiva da comunidade política (polity).

Por outro lado, sob o ponto de vista dos vínculos estabelecidos com as demais realidades normativas, esta prática produz um efeito de "vasos comunicantes" (PONTHOREAU, 2005) que, sem chegar ao ponto de reconhecer a insurgência de uma nova ordem mundial forjada a partir de uma ordem judicial global (SLAUGHTER, 2005), transforma os tribunais nacionais em agentes transnacionais (FERRARESE, 2009; WHYTOCK, 2009). Tem-se, assim, uma dupla ampliação: das realidades institucionais em conversação com o qual as instâncias decisórias nacionais devem se ocupar; e, do próprio repertório de razões a serem colocadas à disposição dos julgadores.

Não se ignora, contudo, que ao adentrarem no universo discursivo dos tribunais constitucionais, estes elementos revestem-se de efeito subversivo (FLETCHER, 1998), desestabilizador (ALFORD, 2005) e irritante (TEUBNER, 1998a), efeitos estes impossíveis de serem previamente controlados.

Levada às últimas consequências, esta prática pode entrelaçar diferentes realidades normativas e propiciar um aumento do interesse pelo outro. Se não um interesse altruístico decorrente de um cosmopolitismo global, mas decorrente da percepção de que a engenhosidade com que outras esferas normativas lidam com os problemas constitucionais de um "outro" pode confrontar, no interior de sua comunidade política, a identidade construída em relação ao “eu”.

\subsection{DIÁlOGO ABERTO E OCULTO: AUMENTO DO REPERTÓRIO NORMATIVO E ESTRATÉGIA ARGUMENTATIVA}

O reconhecimento de que o recurso à comparação consiste em uma estratégia de argumentação (individual ou institucionalmente consideradas) (ANNUS, 2002) implica sejam assumidos alguns pressupostos teóricos.

Não é possível estabelecer um método de comparação adequado a ser aplicado pelas cortes com pretensão de correção21. O uso de fontes estrangeiras é assumido como guia interpretativo e não como resultado de investigação metodologicamente orientada à comparação de diferenças e semelhanças. (ÖRÜCÜ, 1997, p. 253). A pluralidade metódica das cortes afigurase como requisito essencial para que ela possa realizar a devida busca sobre o direitoaplicável ao

21 Frequentemente uma preocupação metódica exacerbada no discurso jurídico, em especial no contexto de justificação da decisão, frequentemente esconde (emascara) as opções ideológicas do intérprete. Cf. a advertência de LAMEGO (1990, p. 96-98).

Revista de Direito Brasileira | São Paulo, SP | v. 20 | n. 8 | p. 62-80 |Mai./Ago. 2018 
caso (afasta-se aqui a possibilidade de qualquer teoria interpretativa exclusivista) (CHOUDHRY, 1999).

Os elementos não-nacionais colocados em conversação nas decisões (a serem traduzidos) afiguram-se como topói argumentativos que são concatenados com os demais materiais normativos. Desta forma, cumprem uma função estratégica pré-definida pelo intérprete e respondem aos anseios de ampliação do repertório normativo posto à disposição das cortes nos processos de argumentação jurídica.

Ao se enfatizar o aspecto instrumental do recurso ao direito comparado tem-se aparentemente uma fragilização da disposição ao diálogo transjudicial. Todavia, trata-se de uma debilidade aparente, pois, ao lhe conferir o caráter de topos argumentativo, autoriza que este elemento atue, concorrentemente, com as demais fontes normativas; o que torna admissível o seu uso, tanto no contexto de decisão, quanto no seu contexto de justificação.

O grau de coerência interna do argumento e o peso a ele atribuído no discurso judicial estão diretamente relacionados com a forma com que se aproxima o intérprete do elemento nãonacional. Exemplificativamente, podem ser destacados: a busca pela identificação de uma origem comum do instituto entre as experiências jurídicas comparadas (aproximação genealógica), a busca pela identificação de equivalentes funcionais, tendo em vista a existência de problemas comuns a serem resolvidos (aproximação funcionalista), a busca de uma identidade própria a partir do diálogo com outras experiências (aproximação expressionista), esta última muito próxima à abordagem dialógica, em especial quando o recurso à experiência estrangeira pretende ser "distinguished from the national practice", em uma atitude de rechaço ao empréstimo.

O contexto externo ao discurso judicial também fornece importantes impulsos para que o tribunal se engaje, em maior ou menor medida, em um maisestreito diálogo constitucional. A escolha deliberada da corte em dialogar com experiências estrangeiras é assumida como "estratégia discursiva" (ANNUS, 2002), como técnica de "fornecimento de razões" (CHOUDHRY, 1999) ou ainda como "parâmetro de crítica da ordem interna" (TUSHNET, 1999).

\section{CONCLUSÃO}

O fenômeno tratado neste artigo (maior abertura das ordens jurídicas e dos tribunais à incorporação de elementos normativos produzidos em outros sistemas de direito) está diretamente relacionado a um processo de erosão e de esfumaçamento das fronteiras jurídicas e da noção de autoridade soberana.

A incorporação desta estratégia argumentativa ao discurso judicial se processa através de diferentes mecanismos que foram aqui tratados sob a metáfora de "tradução jurídica" que veicula a ideia aqui defendida de que a prática dos tribunais representa tanto uma forma de abertura a pluralidade de perspectivas quanto uma estratégia discursiva voltada a produzir pontos de convergência material em torno das atualizações de sentido da constituição.

O reforço desta estratégia comumente é associado à ideia da insurgência de uma nova ordem global e de formação de redes transgovernamentais que se alicerça sobre esses processos de transfertilização, e que apontam para o reconhecimento de processos de convergência material (não sem serem objeto de duras objeções).

Ao optar pela adoção da metáfora de tradução jurídica (ao referir-se a este fenômeno) pretendeu-se incorporar a ideia de que o diálogo e engajamento entre cortes pressupõem: a existência de uma distinção substantiva entre o texto original e o texto traduzido; $o$ reconhecimento de que o ato de tradução representa um ato sempre criativo por parte daquele que empreende o esforço de transposição; e, ainda, a ênfase na transformação dos atores sociais e práticas linguísticas afetadas pelo texto traduzido. 
Engajar-se em traduções representa sempre um ato deliberado, impregnado de sentido persuasivo e que muito mais do que tão-somente representar uma predisposição a ouvir experiências externas (dialogar), representa um ato de força e de reafirmação da autoridade daquele que "voluntariamente" se engaja no esforço de tradução.

Como desdobramento direto desta percepção, pode-se afirmar que a tradução jurídica desempenha múltiplas funções (que variam, inclusive, a partir da natureza do órgão decisório que se envolvem nos esforços de diálogo constitucional). Para além deste recurso à autoridade persuasiva (que lhe é ínsito), pode-se perceber que há graus distintos de utilização deste recurso, se se toma como referência a prática de tribunais não-nacionais e tribunais domésticos.

Sob a perspectiva dos órgãos decisórios não-nacionais, o recurso a esta estratégia se dá com o propósito de incremento de sua legitimidade, como ferramenta hermenêutica para eliminação de eventuais tensões interssistêmicas e, ainda, como forma de estimular que as cortes nacionais se engajem (e implementem) suas diretivas.

Por seu turno, os tribunais domésticos têm igualmente ampliado o recurso a estas práticas como forma de, inclusive, justificar eventual postura de maior ativismo (tendo em vista o empréstimo da autoridade e prestígio de outras cortes judiciais) e de enfrentar questões que envolvem elevados graus de desacordos morais.

Como se teve oportunidade de discutir neste artigo, um preconizado "novo comparativismo" veicula a ideia de que existem elementos de conexão material entre os discursos judiciais, o que converte os tribunais domésticos em autênticos atores transnacionais (por conta da capacidade de influenciar decisões tomadas fora de seus domínios territoriais) e como espaços decisórios com importante papel de neutralização de tensões e conflitos normativos.

Assim, o recurso ao "argumento de direito comparado" se apresenta como um importante mecanismo de articulação de alternativas concorrentes e de neutralização de expectativas. Tanto porque pode recorrer a elas ante demandas "internas" por novos pontos de convergência material (problema da congruência normativa), como para reforçar da autoridade de suas decisões quando confrontados por instâncias decisórias situadas fora dos domínios territoriais do Estado (problema da soberania).

Esse efeito de legitimação, sob o ponto de vista da realidade intracomunitária, permite seja "internalizada" a crítica acerca de suas próprias pré-compreensões (dimensão negativa) e sejam enfeixadas múltiplas alternativas resultantes do compromisso com o pluralismo (dimensão positiva). Frise-se que a referência à constituição nacional como parâmetro de sua atuação acaba por reforçar o fundamento formal de legitimidade de sua atuação e, como dito antes, inovar sem romper com a tradição discursiva da comunidade político (polity).

Por fim, se o argumento aqui defendido estiver correto, é possível aprofundar a discussão sobre como pode ser formulado o processo de fixação de pontos de convergência material e como associar esta busca por legitimidade à estratégia empreendida pelo órgão decisório de se engajar em processos de tradução jurídica. A partir do estudo até aqui empreendido, podem-se apontar as seguintes assertivas a serem discutidas (e provadas) em estudos subsequentes: (a) quanto maior o grau de desacordo, maior dever ser a busca de experiências que possam apresentar respostas aos desafios constitucionais apresentados; (b) quanto maior a articulação entre posturas em diferentes realidades normativas, em princípio, maior será a capacidade de produção de pontos de convergência e formação de identidades no plano doméstico; e, (c) quanto maior o grau de engajamento e de diálogo que se estabeleça entre as diferentes instâncias decisórias em torno de questões constitucionais, em princípio, maiores são as chances de apresentação de alternativas e possibilidades

\section{REFERÊNCIAS BIBLIOGRÁFICAS}


ACKERMAN, Bruce. The rise of world constitutionalism. Virginia Law Review. Charlottesville, VA, USA, v. 83, n. 4, p. 771-797, may 1997.

AJANI, Gianmaria. By chance and prestige: legal transplants in Russia and Eastern Europe. The American Journal of comparative law. Berkeley, ASCL, v. 43, n. 1, p.93-117, 1995.

ALEXY, Robert. Teoria da argumentação jurídica: a teoria do discurso racional como teoria da justificação jurídica 2.ed. Belo Horizonte: Landy, 2005.

ALFORD, Roger. In search of a theory for constitutional comparativism. University of California Los Angeles Law Review, v. 52, n. 3, p. 640-714, feb. 2005.

ANNUS, Taavi. Comparative Constitutional Reasoning: the law and strategy of selecting the right arguments. Duke Journal of Comparative and International Law. Durham, North Caroline, US, Duke University, v. 14, p. 301-349, Fall 2004. Disponível em: <http://www.law.duke.edu/journals/djcil/articles/djcil14p301.htm>. Acesso em: 13 dez. 2006.

BASTOS JR, Luiz Magno Pinto; BUNN, Alini. Constitutional dialogue ad extra: the discursive practice of the Federal Supreme Court, of the use of "argument of comparative law". In: The constitutional implications of the Regulatory State, 2008, Londres. The constitutional implications of the Regulatory State.Londres: UCL/IACL, 2008

CANÇADO TRINDADE, Antonio Augusto [2002a]. Os rumos do direito internacional contemporâneo: de um jus inter gentes a um novo jus gentium no século XXI. In: ___ . O direito internacional em um mundo em transformação. Rio de Janeiro: Renovar, 2002. p. 10391109.

. [2002b]. Reflections on international law-making customary international law and the reconstruction of jus gentium.In: __ O direito internacional em um mundo em transformação. Rio de Janeiro: Renovar, 2002. p. 77-90.

CHOUDHRY, Sujit. Globalization in search of justification: toward a theory of comparative constitutional interpretation. Indiana Law Journal, v. 74, n.3, p. 819-948, Summer 1999.

Migration as a new metaphor in comparative constitutional law. In: (ed). The migration of constitutional ideas. Cambridge: Cambridge University Press, 2006. p. 1-36.

CURRAN, Vivian Grosswald. Comparative law and language. In: REIMANN, M.; ZIMMERMANN, R. (eds.). The Oxford Handbook of Comparative Law. Oxford: OUP, 2006. p. 675-708.

DAMMANN, Jens. The role of comparative law in statutory and constitutional interpretation. St. Thomas Law Review, Miami, v. 14, n. 3, p. 513-559, 2002.

DAVI, René. Os grandes sistemas de direito contemporâneo. São Paulo: Martins Fontes, 1996.

DE WET, Erika. The international constitutional order. International and Comparative Law Quarterly. v. 55, n. 1, p. 51-76, 2006. 
DELMAS-MARTY, Mireille.Três desafios para um direito mundial. Rio de Janeiro: Lumen Juris, 2003.

. Comparative law and the internationalisation of law in Europe. In: VAN HOECKE, M. (ed.). Epistemology and methodology of comparative law. Oxford: Hart Publishing, 2004. p. $247-$ 258.

DI RUFFIA, Paolo Biscaretti. Introdución al derecho constitucional comparado: las "formas de Estado" y las "formas de gobierno", las constituciones modernas. México: Fondo de Cultura Económica, 2000.

DROBNIG, Ulrich. The use of comparative law by courts. In: DROBNIG, U.; VAN ERP, S. (eds.). The use of comparative law by courts.Kluwer Law International, 1997. p. 3-24.

DUPRÉ, Catherine. Importing the law in post-communist transitions: the Hungarian constitutional court and the right to human dignity. Oxford: Hart Publishing, 2003.

FASSBENDER, Bardo. The United Nations Charter as constitution of the international community. Columbia Journal of Transnational Law, v. 36, p. 529-619, 1998.

FERRARESE, Maria Rosaria.When national actors become transnational: transjudicial dialogue between democracy and constitutionalism.Global Jurist: frontiers, v. 9, n. 1, article 2, 2009. Disponível em: 〈http:॥ www.bepress.com/gj/vol9/iss1/art2>.

FIORAVANTI, Maurizio. Los derechos fundamentales: apuntes de historia de las constituciones. 2.ed. Madrid: Trotta, 1998.

. Constitución: de la antigüedad a nuestros días. Madrid: Trotta, 2001.

FLETCHER, George P. Comparative law as a subversive discipline. The American Journal of comparative law. Berkeley, ASCL, v. 46, n. 4, p.683-700, 1998

FRANKENBERG, Günther. Critical comparisons: re-thinking comparative law. Harvard International Law Journal, v. 6, p. 411-445, 1985.

GARCÍA-PELAYO, Manuel. Derecho constitucional comparado. Madrid: Alianza Universidad, 1993.

GLENN, H. Patrick. Persuasive Authority.McGill Law Journal, v. 32, p. 261-299, 1987.

HÄBERLE, Peter. Elementos teóricos de un modelo general de recepción jurídica. In: PÉREZLUÑO, A.E. (Org.). Derechos humanos y constitucionalismo ante el tercer milenio. Madrid: Marcial Pons, 1996. p. 151-185.

HARDING, Sarah. Comparative reasoning and judicial review.The Yale Journal of International Law, v. 28, n. 2, p. 409-464, 2003.

HIRSCHL, Ran. Towards juristocracy: the origins and consequences of the new constitutionalism. Cambridge: Harvard Univesity Press, 2007. 
JACKSON, Vicki. Narratives of federalism: of continuities and comparative constitutional experience. Duke Law Journal, v. 51, n. 1, p. 223-288, 2001.

. Constitutional engagement in a transitional era. Oxford: Oxford, 2010.

JACOBSOHN, Gary Jeffrey. The permeability of constitutional borders.Texas Law Review, v. 82, n. 7, p. 1763-1818, 2004.

. Constitutional identity. Cambridge, MA; London: Harvard University Press, 2010.

KIIKERI, Markku. Comparative legal reasoning and European law. Dordrecht: Kluwer, Law and philosophy library, v. 50, 2001.

KOOPMANS, Thijmen. Comparative law and the courts. International and Comparative Law Quarterly. Cambridge Journals, v.45, n. 3, p. 545-556, 1996.

LANGER, Máximo. From legal transplants to legal translations: the globalization of plea bargaining and the americanization thesis in criminal procedure. Harvard International Law Journal, v. 45, n. 1, p. 1-64, 2004.

LEGAIS, Raymond. France: L'utilisation du droit comparé par les Tribunaux: rapport français. In: DROBNIG, U.; VAN ERP, S. (eds.). The use of comparative law by courts. Kluwer Law International, 1997. p. 113-126.

LOLLINI, Andrea. La circolazione degli argumenti: metodo comparato e parametri interpretativi extra-sistemici nella giurisprudenza costituzionale sudafricana. Diritto Pubblico e Comparato Europeo, n. 1, 2007. Disponível em: www.jus.unitn.it/cardozo/Review/2007/lollini2.pdf. Acesso em: 12 jan. 2007.

MATTEUCCI, Nicola. Organización del poder y libertad: historia del constitucionalismo moderno. Madrid: Trotta, 1998.

McCRUDDEN, Christopher. A common law of human rights: transnational judicial conversations on constitutional rights. Oxford Journal of Legal Studies, v. 20, n. 4, p. 499-532, 2000.

MICHAELS, Ralf. The functional method of comparative law. In: REIMANN, M.; ZIMMERMANN, R. (eds.). The Oxford Handbook of Comparative Law. Oxford: OUP, 2006. p. 339-382.

NELKEN, David Legal transplants and beyond: of disciplines and metaphors. In: HARDING, A.; ÖRÜCÜ, E. (eds.). Comparative law in the 21st century. London; The Hague; New York: Kluwer Academic Publishers, 2002. p.19-34.

Comparatists and transferability. In: LEGRAND, P; MUNDAY, R (Eds). Comparative legal studies: traditions and transitions. Cambridge: Cambridge, 2003. p. 437-466

ÖRÜCÜ, Esin. Comparative law in practice: the courts and the legislator. In: ÖRÜCÜ, E.; NELKEN, D. (Eds.). Comparative law: a handbook. Oxford; Portland: Hart Publishing, 2007. p. 411-434. 
PARRISH, Austen L. Storm in a teacup: the U.S. Supreme court's use of foreign law. University of Illinois Law Review. v. 2, p. 637-680, 2007.

PEGORARO, Lucio. La utilización del derecho comparado por parte de las cortes constitucionales: un análisis comparado. Palestra del Tribunal Constitucional, Lima, a. 2, n. 7, p. 697-730, jul. 2007.

PERJU, Vlad. The Puzzling Parameters of the Foreign Law Debate.Utah Law Review. v. 2007, n. 1, p. 167-214, 2007.

PERNICE, Infolf. Multilevel constitutionalism in the European Union. WHI Paper, Walter Hallstein-Institut für Europäisches Verfassungsrecht Humboldt-Universität zu Berlin, Paper n. 5, 2002.

POIRIER, Johanne. Belgique. In: The constitutional implications of the Regulatory State, 2008, Londres. The constitutional implications of the Regulatory State. Londres: UCL/IACL, 2008.

PONTHOREAU, Marie-Claire. Le recours à <l'argument de droit comparé> par le judge constitutionnel. Quelques problèmes théoriques et techniques. In: MELIN-SOUCRAMANIEN, Ferdinand. L'interpretation constitutionnelle. Paris: Dalloz, 2005. p. 167-184.

SACCO, Rodolfo. Introdução ao direito comparado. São Paulo: RT, 2001.

SANCHEZ AGESTA, Luís. Curso de derecho constitucional comparado. 5.ed. Madrid: Universidad de Madrid, 1974.

SAUNDERS, Cheryl. The use and misuse of comparative constitutional law. Indiana Journal of Global Legal Studies. Bloomington, IN, v. 13, n.1, p. 37-76, 2006.

SCHEPPELE, Kim Lane. Aspirational and aversive constitutionalism: the case for studying cross-constitutional influence through negative models. I-CON International Journal of Constitutional Law.New York/US, Oxford Journals/New York University School of Law, v. 1, n. 2, p.296-324, 2003.

. The migration of anti-constitutional ideas: the post-9/11 globalization of public law and the international state of emergency. In: CHOUDHRY, S. (ed). The migration of constitutional ideas. Cambridge: Cambridge University Press, 2006. p. 347-373.

SCHUTTER, Olivier de.The implementation of the EU Charter of fundamental rights through the open method of coordination.Jean Monnet Working Paper, New Your School of Law, Paper n. 7, 2004.

SLAUGHTER, Anne-Marie.A typology of transjudicial communication.University of Richmond Law Review. v. 29, p. 99-138, a. 1994.

[2004a]. A new world order. Princeton: Princeton U. Press, 2004.

[2004b]. Defining the limits: universal jurisdiction and national courts. In: MACEDO, Stephen (ed.). Universal jurisdiction: national courts and the prosecution of serious crimes under international law. Philadelphia: University of Pennsylvania Press, 2004. p. 168-192. 
A brave new judicial world. In: IGNATIEFF, Michael (Ed). American Exceptionalism and Human Rights. Princeton: Princeton University Press, 2005.

SLAUGHTER, Anne-Marie; BURKE-WHITE, William An international constitutional moment.Harvard International Law Journal, v. 43, n. 2, p. 1-21, 2002.

TATE, Neal; VALLINDER, Torbjörn.The Global Expansion of judicial power. New York: New York University Press, 1995.

TEUBNER, Gunther. [1998a]. Legal irritants: good faith in British law or how unifying law ends up in new divergences. The modern law review, v. 61, n. 1, p. 11-32, 1998.

. [1998b]. Two faces of Janus: rethinking legal pluralism. In: TUORI, K.; UUSITALO, J.; BANKOWSKI, Z. (eds.). Law and power: critical and socio-legal essays. Liverpool: Deborah Charles, 1998. p. 119-140.

Societal constitutionalism: alternatives to state-centred constitutional theory. (Storrs Lectures 2003/04.Yale Law School). In: JOERGES, Inger-Johanne; TEUBNER, Gunther (eds.). Transnational Governance and Constititionalism. Oxford: Hart Publishing, 2004. p. 3-28 Disponível em: <http://www.jura.unifrankfurt.de/fb/fb01/ifawz1/teubner/dokumente/societal_constitutionalism.pdf>.

TUSHNET, Mark The possibilities of comparative constitutional law. The Yale Law Journal. New Haven, CT, v. 108, n. 6, p. 1225-1309, abr 1999.

WATSON, Alan. Aspects of reception of law. The American Journal of comparative law. Berkeley, ASCL, v. 44, n. 2, p.335-351, 1998.

WHYTOCK, Christopher. Domestic courts and global governance.Tulena Law Review, v. 84, n. 1, p. 69-123, 2009.

YAZBEK, Otávio Considerações sobre a circulação e transferência dos modelos jurídicos. In: GRAU, Eros Roberto; GUERRA FILHO, Willis Santiago (Orgs.). Direito constitucional: estudos em homenagem a Paulo Bonavides. São Paulo: Malheiros, 2001. p. 540-556.

ZAGREBELSKY, Gustavo. El derecho ductil: ley, derechos y justicia. Madrid: Trotta, 1995. 